\title{
Perancangan Data Warehouse Untuk Sistem Akademik STMIK Kadiri
}

\section{Data Warehouse System Design for Academic STMIK Kadiri}

\author{
Umi Fadilah $^{1}$, Wing Wahyu Winarno ${ }^{2}$, Armadyah Amborowati ${ }^{3}$ \\ STMIK AMIKOM Yogyakarta \\ Magister Teknik Informatika STMIK AMIKOM Yogyakarta \\ farilah_07@yahoo.co.id ${ }^{3}$,wing@amikom.ac.id ${ }^{2}$, armadyah.a@amikom.ac.id ${ }^{3}$
}

\begin{abstract}
Abstrak
Data akademik merupakan data penting dalam perguruan tinggi. Informasi mengenai data akademik di butuhkan oleh pihak manajemen untuk mengetahui kondisinya. Informasi yang tersedia pada database sistem informasi akademik belum dimanfaatkan sebagai pendukung pengambilan keputusan hanya bersifat transaksional untuk itu perlu menerapkan suatu data warehouse untuk menampung data untuk diolah menjadi informasi yang berguna bagi manajemen.Penelitian ini membahas masalah perancangan data warehouse serta mengimplementasikannya. Sumber data yang digunakan adalah database akademik yang ada di STMIK Kadiri dan data warehouse yang dibangun berdasarkan tabel fakta mahasiswa. Metode yang digunakan adalah metode penelitian tindakan yaitu menggunakan action research diantaranya tahap Observe, tahap Reflect, Plan dan Act. Di dalam tahap-tahap tersebut dimulai dari merencanakan subyek data, merancang skema bintang, merancang data warehouse kemudian di implementasikan dengan cara Extract, Transform, load membentuk cube dan menyajikan data untuk laporan yang dibutuhkan manajemen. Hasil dari penelitian ini adalah rancangan data warehouse akademik yang sesuai dengan STMIK Kadiri dan menghasilkan laporan tentang jumlah mahasiswa per angkatan, per jenis kelamin dan per kota asal mahasiswa. Data warehouse ini dibangun dengan SQL Server 2008 dan penyajian data dengan Excel Powerpivot.
\end{abstract}

Kata Kunci : Database, Skema Bintang, ETL, Data Warehouse, Powerpivot

\begin{abstract}
Academic data is an important data in college. Information on academic data needed by management to determine its condition. The information available in the database of academic information system has not been used for decision support transactional only to the need to implement a data warehouse to accommodate the data to be processed into useful information for management.This study addressed the issue of data warehouse design and implement. The data used is academic databases that exist in STMIK Kadiri and data warehouse built on the fact table student. The method used is action research method is to use action research stages include Observe, Reflect stage, Plan and Act. Within these stages starting from plotting the data subject, designing a star schema, designing a data warehouse then be implemented by way of Extract, Transform, load form a cube and present data for management reports as required.The results of this research is to design a data warehouse appropriate academic STMIK Kadiri and generate reports on the number of students per class, per sex and per the student's home town. The data warehouse is built with SQL Server 2008 and presenting data with Excel PowerPivot.
\end{abstract}

Keywords: Database,Star Schema,ETL, DataWarehouse, PowerPivot.

\section{PENDAHULUAN}

Sekolah Tinggi Manajemen Informatika dan Komputer Kadiri atau yang lebih dikenal dengan nama "STMIK Kadiri" adalah sekolah tinggi yang telah memiliki sistem informasi akademik namun di sistem tersebut sistem tersebut masih terdapat kekurangan 
yakni sistem tersebut tidak terintegrasi didalam satu basisdata. Pengelolaan data akademik yang di gunakan secara online dan manual. Data akademik secara online telah dimiliki oleh

STMIK Kadiri yang terintegrasi kedalam sebuah database yang dimulai tahun akademik 2009 dan tahun akademik 2015, sedangkan data yang manual merupakan data yang sudah lama berjalan dimulai tahun 2001 sampai tahun 2008, yang tidak di arsipkan dalam sebuah basisdata yang terintegrasi.

Setiap pengelolaan tiap semester harus membuat tabel sendiri serta data yang tidak ternormalisasi. Data tersebut sulit untuk diintegrasikan ke dalam sebuah database, sehingga dalam proses pengolahan informasinya belum akurat dan tepat. Hal ini juga berdampak pada penyajian informasi ke pihak toplevel- management untuk pengambilan keputusan guna meningkatkan mutu institusi dalam bidang akademik menjadi terhambat. Oleh karena itu, di institusi ini akan dikembangkan sebuah data warehouse yang mampu mengintegrasikan data dan menyimpannya untuk jangka waktu yang lama.

Data warehouse adalah koleksi data yang bersifat subjectoriented, terintegrasi, timevariant, dan non-volatile yang digunakan untuk mendukung proses pengambilan keputusan yang trategis organisasi [1]. Data yang ada pada perguruan tinggi yang begitu besar dan banyak membutuhkan alokasi tempat penyimpanan akan terbantu dan menjadi efisien dengan adanya data warehouse [2]. Dengan adanya data warehouse dapat ditangkap seluruh proses bisnis yang ada dari mulai yang berhadapan dengan mahasiswa sebagai konsumen, proses pengajaran dan keseluruhan sistem informasi yang ada dalam perguruan tinggi [3]. Penggunaan data warehouse untuk menunjang kegiatan akademik telah banyak dilakukan. Bagaimana mengelola basisdata perguruan tinggi yang baik menggunakan datawarehouse misalnya telah dilakukan oleh Warnars [4].

Penggunaan data warehouse lebih efisien jika dibandingkan dengan menggunakan OLTP. Ariana dan Sucahyo mengembangkan data warehouse untuk menunjang kegiatan akademik di perguruan tinggi. Dengan adanya data warehouse, proses penyusunan laporan menjadi lebih sederhana, karena pengguna bisa melakukan customization report sesuai dengan yang diinginkan, sehingga ada efisiensi waktu dari yang sebelumnya memerlukan waktu satu bulan untuk membuat program baru atau satu minggu untuk mengerjakan secara manual menjadi hanya satu hari [5].

Paper ini akan membahas perancangan data warehouse untuk sistem akademik di STMIK Kadiri yang memiliki basisdata yang belum terintegrasi dengan baik, dimana terdapat dua sistem informasi akademik yang pengelolaannya masih bersifat ad-hoc.Penelitian ini mampu menghasilkan basisdata yang terintegrasi dengan baik dan pelaporan yang relatif lebih cepat menggunakan SQL Server [8].

\section{METODE PENELITIAN}

Dalam penelitian ini menggunakan metode penelitain action research. Action research merupakan penelitian yang berfokus langsung pada tindakan sosial. Penelitian tindakan yaitu penelitian baik kualitatif maupun kuantitatif. Penelitian tindakan ini merupakan metode yang didasari pada tindakan masyarakat yang sering diselenggarakan pada suatu latar yang luas, seperti rumah sakit, pabrik, sekolah dan lain sebagainya[7].

\subsection{Metode Pengumpulan Data}

Pada penelitian ini dilakukan beberapa metode pengumpulan data. Metode pengumpulan data disesuaikan dengan jenis data yang akan dikumpulkan yaitu teknik untuk pengumpulan data primer dan teknik untuk pengumpulan data sekunder. 


\subsubsection{Data Primer}

Pengumpulan data primer pada penelitian ini dilakukan dengan metode observasi dan wawancara. Adapun pengumpulan data primer pada penelitian ini adalah :

1. Observasi, data yang diperoleh dari penelitian di STMIK Kadiri adalah :
a. Master Data Mahasiswa.
b. Master Data Mata Kuliah
c. Master Data Dosen
d. Master Data Jadwal Kuliah.
e. Master Data Transaksi Kuliah Mahasiswa
f. Master Data Nilai Mahasiswa
g. Master Data Kelulusan Mahasiswa.
h. Master Data Transaksi Dosen Mengajar
i. Master Data Status Mahasiswa

2. Wawancara, dengan cara bertanya langsung kepada responden.

\subsubsection{Data Sekunder}

Data sekunder dalam penelitian ini diperoleh dari sumber-sumber kepustakaan yang relevan, hasil penelitian sebelumnya yang bersifat mutakhir, informasi tentang teori-teori yang berhubungan dengan pokok permasalahan yang diteliti serta data-data laporan yang terjadi di Prodi STMIK Kadiri yang selama ini terjadi.

\subsection{Metode Analisis Data}

Metode analisa data yang digunakan penulis pada penelitian ini menggunakan pemodelan data multidimensi atau sering disebut Nine Step Design Method. Proses analisa dilakukan terhadap hasil tahapan pengumpulan data dengan pengamatan, wawancara, dan studi literatur untuk mendapatkan spesifikasi kebutuhan sistem yang akan dikembangkan. Sembilan tahap dalam perancangan database untuk data warehouse, yaitu [8] :
a. Memilih Proses.
b. Menentukan grain atau sumber dari proses bisnis.
c. Mengindentifikasi dan penyesuaian dimensi.
d. Memilih Fakta
e. Menyimpan Perhitungan awal dalam tabel fakta.
f. Melihat kembali tabel dimensi.
g. Memilih durasi database.
h. Menelusuri perubahan dari dimensi.
i. Memutuskan prioritas query dan tipe query, memilih physical design.

2.3. Alur Penelitian

Untuk mengetahui jalannya penelitian pada gambar dibawah ini : 


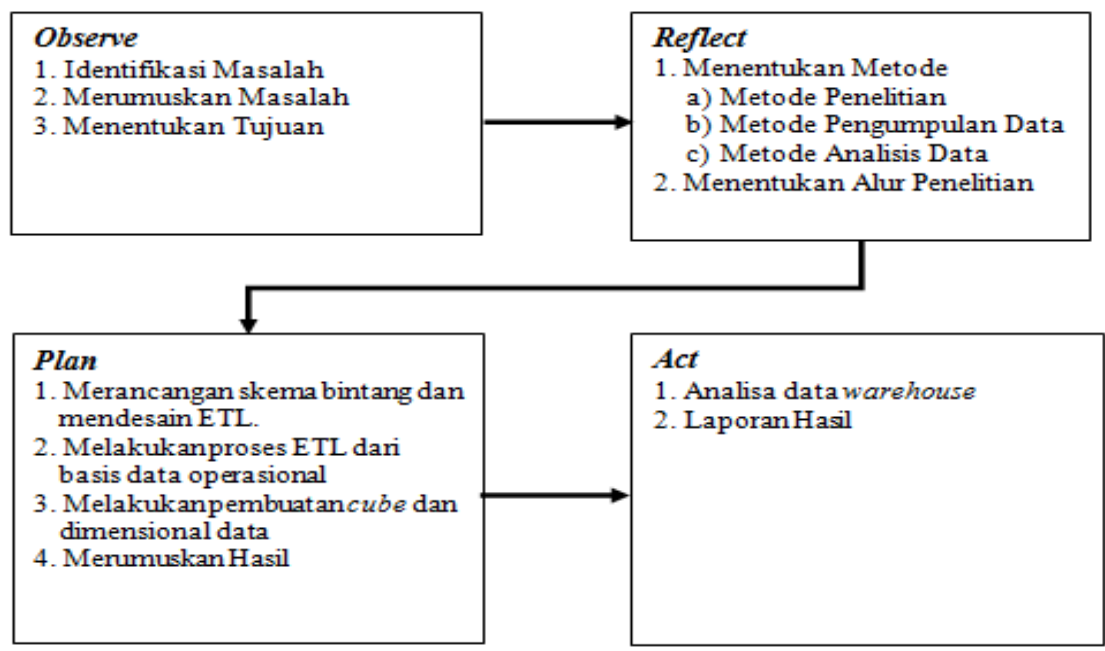

Gambar 1. Alur Penelitian

1. Tahap Perencanaan

3. HASIL DAN PEMBAHASAN

a) Analisis Subjek Data

Fungsi bisnis perguruan tinggi di Tunjukkan pada tabel 1.

\begin{tabular}{|c|l|l|}
\hline Kategori Data & \multicolumn{1}{|c|}{ Detil Jenis Informasi } & \multicolumn{1}{|c|}{ Sumber Database } \\
\hline \multirow{4}{*}{ Mahasiswa } & Promosi dan Pendaftaran & SIAK \\
\cline { 2 - 3 } & Seleksi dan Calon Mahasiswa & SIAK \\
\cline { 2 - 3 } & Registrasi dan OBM & SIAK \\
\cline { 2 - 3 } & Aktifitas Mahasiswa & SIAK \\
\cline { 2 - 3 } & Pelayanan Informasi & SIAK \\
\cline { 2 - 3 } & Keuangan Mahasiswa & SIAK \\
\hline \multirow{5}{*}{ Perkuliahan } & Kapasitas Ruangan Pembelajaran & SIAK \\
\cline { 2 - 3 } & $\begin{array}{l}\text { Persentase Kepadatan Ruangan } \\
\text { Pembelajaran }\end{array}$ & SIAK \\
\cline { 2 - 3 } & $\begin{array}{l}\text { Pengajar dan Mata Kuliah yang } \\
\text { diampu per Semester }\end{array}$ & SIAK \\
\cline { 2 - 3 } & $\begin{array}{l}\text { Kategori dan Nama Tiap Mata } \\
\text { Kuliah }\end{array}$ & SIAK \\
\hline \multirow{5}{*}{ Kurikulum } & Pengembangan Kurikulum & SIAK \\
\cline { 2 - 3 } & Pengembangan Materi & SIAK \\
\hline \multirow{4}{*}{ Dosen } & Rekrutmen Dosen & SIAK \\
\cline { 2 - 3 } & Aktifitas Dosen & SIAK \\
\cline { 2 - 3 } & Evaluasi dan Pengembangan Dosen & SIAK \\
\hline \multirow{2}{*}{ Alumni } & Registrasi Alumni & SIAK \\
\cline { 2 - 3 } & Layanan Alumni & SIAK \\
\hline
\end{tabular}

Berdasarkan proses dan fungsi bisnis tersebut diatas, maka subjek data di sekolah tinggi terdiri dari : mahasiswa,dosen,perkuliahan,kurikulum,dan sebagainya, seperti ditunjukkan pada tabel 2 dibawah ini : 


\begin{tabular}{|l|}
\hline \multicolumn{1}{|c|}{ Kategori Data } \\
\hline Mahasiswa \\
\hline Jadwal Perkuliahan \\
\hline Rencana Studi \\
\hline Absensi Kuliah \\
\hline Matakuliah \\
\hline Nilai Mahasiswa \\
\hline Alumni \\
\hline Dosen \\
\hline Aktifitas Dosen \\
\hline Presensi Dosen \\
\hline Kurikulum \\
\hline Bahan Kuliah \\
\hline Laboratorium \\
\hline Perpustakaan \\
\hline Kegiatan Mahasiwa \\
\hline Keuangan Mahasiswa \\
\hline Keuangan Dosen \\
\hline Fasilitas Kuliah \\
\hline Asisten Dosen \\
\hline
\end{tabular}

Berdasarkan subjek data diatas maka subyek data yang di perlukan untuk pembuatan laporan manajemen ditunjukkan pada tabel 3 dibawah ini :

\begin{tabular}{|c|l|}
\hline Kategori Data & \multicolumn{1}{|c|}{ Kelompok Informasi } \\
\hline \multirow{3}{*}{ Mahasiswa } & Data Pribadi \\
\cline { 2 - 2 } & Data Akademik \\
\cline { 2 - 2 } & Data Nilai \\
\hline \multirow{2}{*}{ Nilai } & Nilai Mahasiswa \\
\cline { 2 - 2 } & KHS \\
\hline
\end{tabular}

Informasi Yang Dibutuhkan

Pihak pengelola sekolah tinggi membutuhkan informasi akademik untuk mendukung pengambilan kebijakan strategis dalam upaya untuk meningkatkan kemajuan dan memudahkan melihat data untuk pengisian borang akreditasi yaitu diantaranya:

1. Laporan jumlah mahasiswa per kota, angkatan, per jenis kelamin.

2. Laporan jumlah mahasiswa per status awal masuk, per status pernikahan, dan per status keaktifan mahasiswa. 
3. Laporan jumlah mahasiswa per kota per angkatan.

Data yang diperlukan untuk membangun data warehouse akademik bersumber dari database akademik kampus, tidak semua data yang ada pada database akademik digunakan untuk pembangungan data warehouse, hanya data yang berkaitan dan diperlukan untuk kebutuhan pembuatan laporan yang diinginkan manejemen saja. Data akademik yang digunakan sebagai data sumber untuk menampilkan laporan adalah:

1. Tabel mahasiswa.

2. Tabel statusawal.

3. Tabel statusmhsw.

4. Tabel statussipil

\section{b). Pemodelan Data}

Model data yang digunakan untuk pemodelan data adalah pendekatan star schema. Pendekatan ini digunakan karena rancangan star schema multidimensi dapat memanfaatkan peran utama tabel dimensi untuk mendukung catatan data dengan deskripsi dan informasi lain dengan entitas yang terlibat $[8,9]$. Tabel-tabel dimensi yang membentuk tabel fakta dapat didukung oleh tabel lain yang lebih detail dan membentuk model star. Model star schema juga dikenal sebagai DW schema untuk analisis multi dimensional [10]. dimana terdapat satu tabel fakta dan beberapa tabel dimensi (Gambar 4).

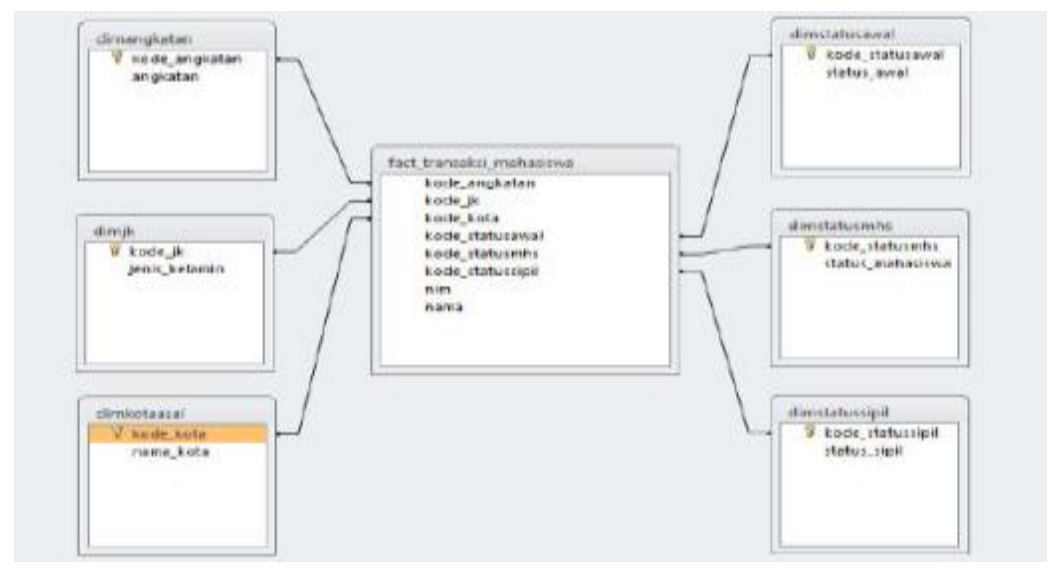

Gambar 4. Rancangan Skema Bintang

2). Tahap Tindakan

Pada tahap ini dilakukan proses pemindahan data dari sumber data ke dalam database data warehouse dengan cara ekstrak,transformation dan load.

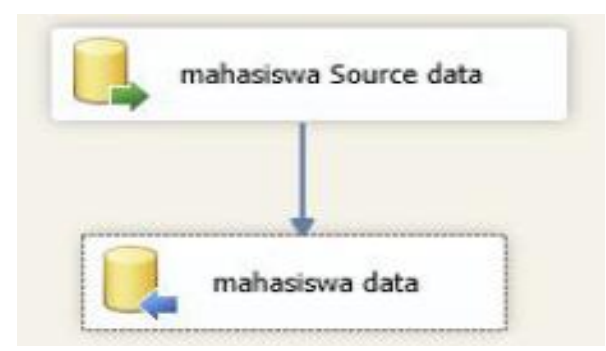

Gambar 5. Proses Pemindahan Data 
Hasil yang diperoleh setelah data dilakukkan pemindahan dari database di tunjukkan pada Gambar 5 dengan melakukkan query:

Select * from mahasiswa

\begin{tabular}{|c|c|c|c|c|c|c|c|c|}
\hline \multicolumn{9}{|c|}{ Results Messages } \\
\hline & nsmhs_nimhs & \multirow{2}{*}{$\begin{array}{l}\text { mspti_kdpti } \\
073112\end{array}$} & \multirow{2}{*}{$\begin{array}{l}\text { tbpst_kdpst } \\
57201\end{array}$} & msmhs_kdjen & msmhs_nmmhs & msmhs_tplhr & msmhs_tglhr & $\mathrm{ms} \wedge$ \\
\hline 1 & 10110676 & & & $\mathrm{C}$ & ERVAN ARYANTO & KEDIRI & $1984-12-1100: 00: 00.000$ & $\mathrm{~L}$ \\
\hline 2 & 10110609 & 073112 & 57201 & $\mathrm{C}$ & ERVAN ARIES SETIANTO & MADIUN & $1985-04-14$ 00:00:00.000 & $\mathrm{L}$ \\
\hline 3 & 11110763 & 073112 & 57201 & C & HENNY RAHMAWATI & KEDIRI & $1987-11-3000: 00: 00.000$ & $P$ \\
\hline 4 & 10110656 & 073112 & 57201 & C & R.T MAHENDRA B.K & KEDIRI & $1981-04-2700: 00: 00.000$ & $\mathrm{~L}$ \\
\hline 5 & 10110626 & 073112 & 57201 & $\mathrm{C}$ & MUHAMMAD SARKOWI & KEDIRI & $1986-01-1000: 00: 00.000$ & $\mathrm{~L}$ \\
\hline 6 & 10110671 & 073112 & 57201 & $\mathrm{C}$ & SUPRAPTI & NGANJUK & $1986-06-1600: 00: 00.000$ & $\mathrm{~L}$ \\
\hline 7 & & 073112 & 57201 & $\mathrm{C}$ & MAYA DWI INDRA KUSTARINI & JOMBANG & $1900-01-01$ 00:00:00.000 & $\mathrm{P}$ \\
\hline 8 & & 073112 & 57201 & $\mathrm{C}$ & MAYA DWI INDRA KUSTARINI & JOMBANG & $1900-01-01$ 00:00:00.000 & $\mathrm{P}$ \\
\hline 9 & 10110657 & 073112 & 57201 & $\mathrm{C}$ & RAGIEL KUSUMA PUTRA & BEKASI & $1990-12-24$ 00:00:00.000 & $\mathrm{L}-$ \\
\hline 1 & III & & & & & & & 1 \\
\hline & executed & sstully. & & & AULIYA-VAIO \STMIK (10.50 & SP2) $\quad$ sa (81) & \begin{tabular}{l|l|l} 
master & $00: 00: 00$ & $766 \mathrm{r}$
\end{tabular} & ows \\
\hline
\end{tabular}

Gambar 6. Hasil query Pemindahan Data

\section{3). Tahap Analisis}

Tahap ini selanjutnya adalah tahap membentuk cube dengan sql server supaya dapat ditransfer ke dalam powerpivot excel untuk kebutuhan analisis datanya secara interaktif menggunakan pivottable supaya menjadi laporan yang bermanfaat bagi pihak manajemen khususnya untuk laporan EPSBED.

a). Pembuatan nama ANALISIS_STMIK

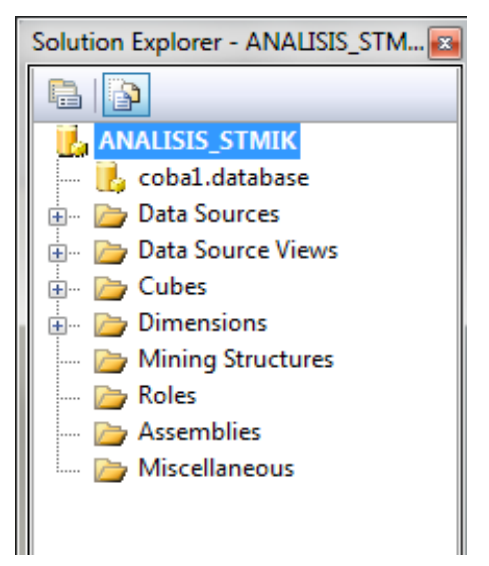

b). Pembuatan Data Source Views

Gambar 7. Pembuatan Data Source 


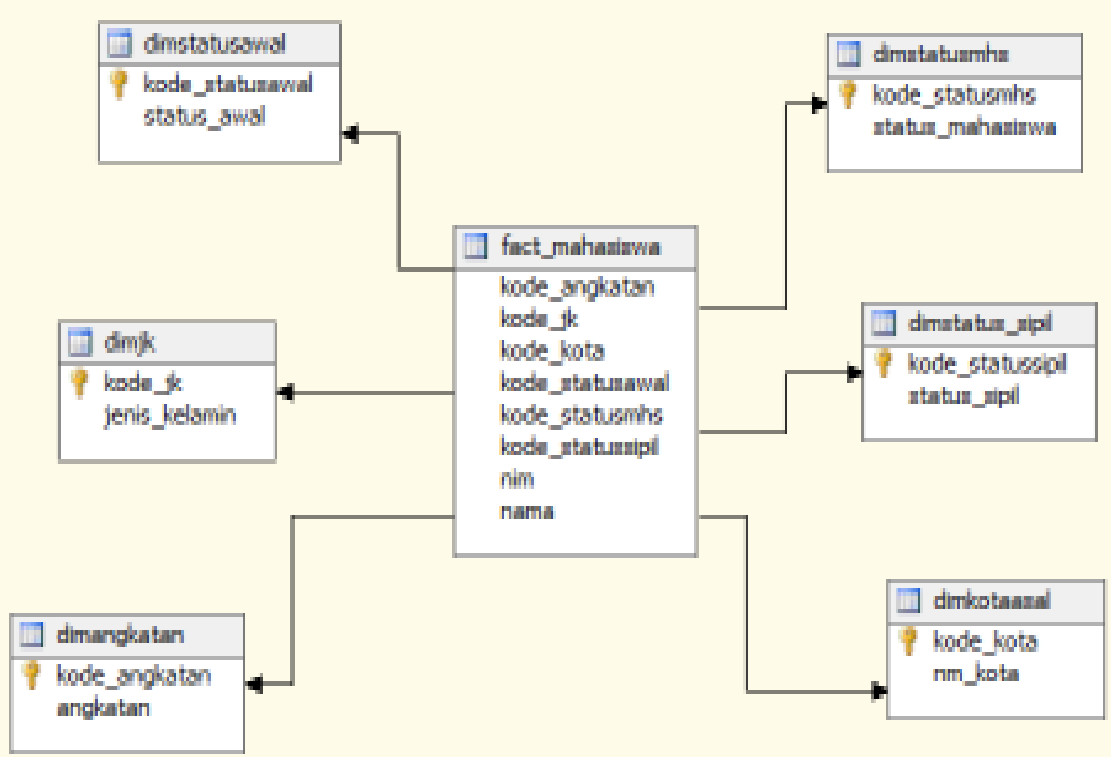

c). Pembuatan Cube

Gambar 8. Pembuatan Data Source Views

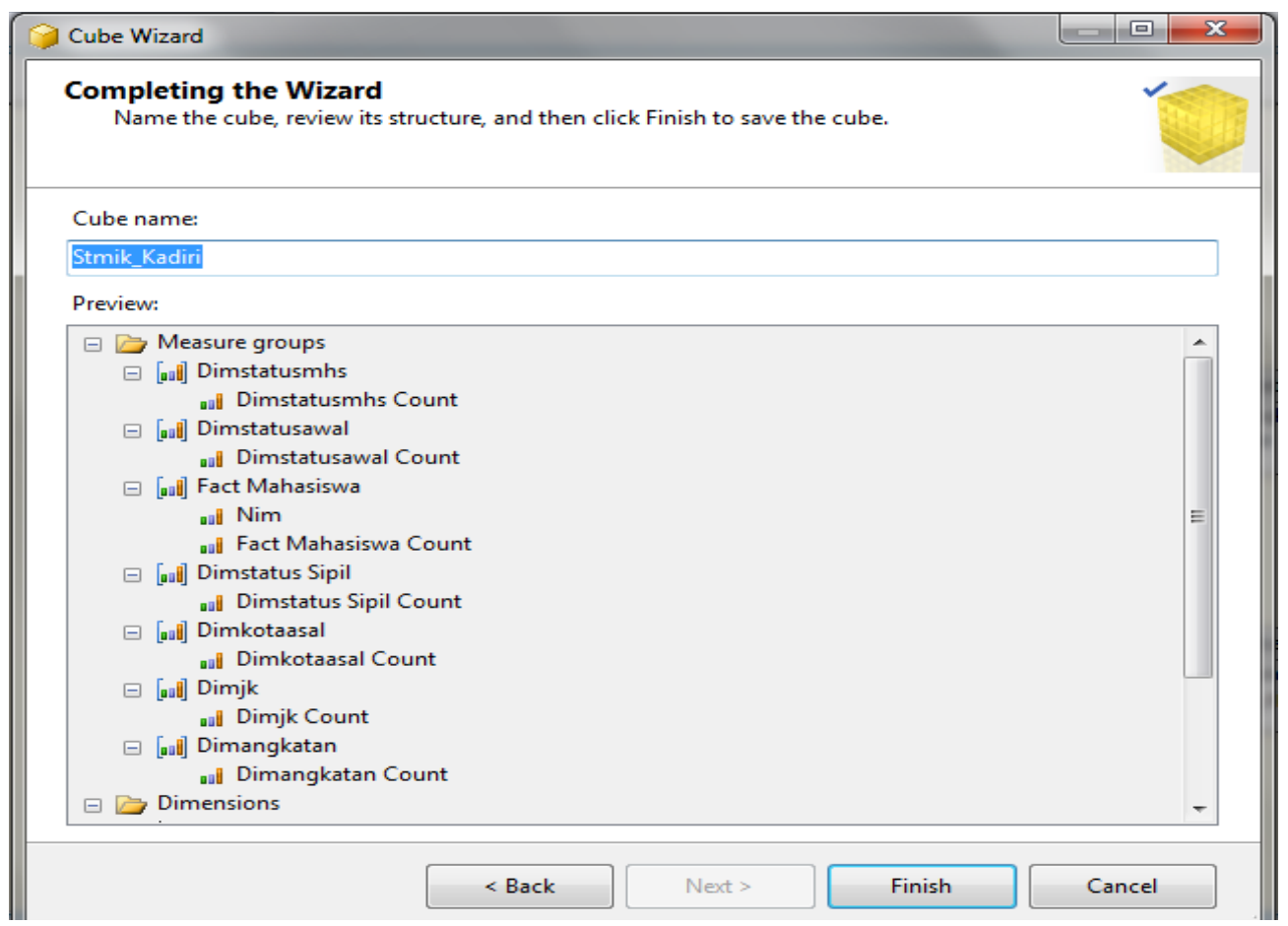

Gambar 9. Pembuatan Cube

d). Pembuatan Dimensi 


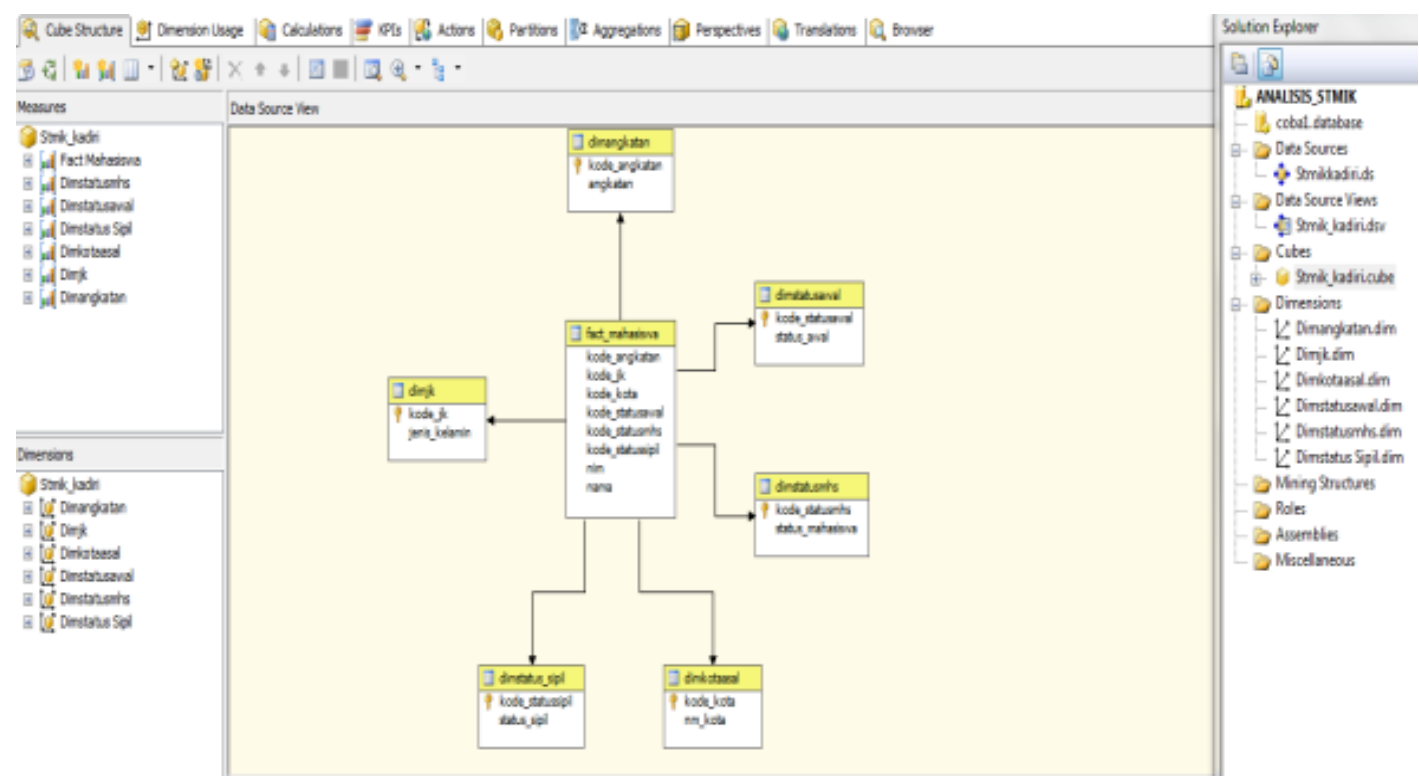

Gambar 10. Pembuatan Dimensi

4). Tahap Refleksi

a. Penyajian Data

Pada tahap ini cara menyajikan data dengan menggunakan powerpivot excel. Data yang akan ditampilkan adalah sebagai berikut :

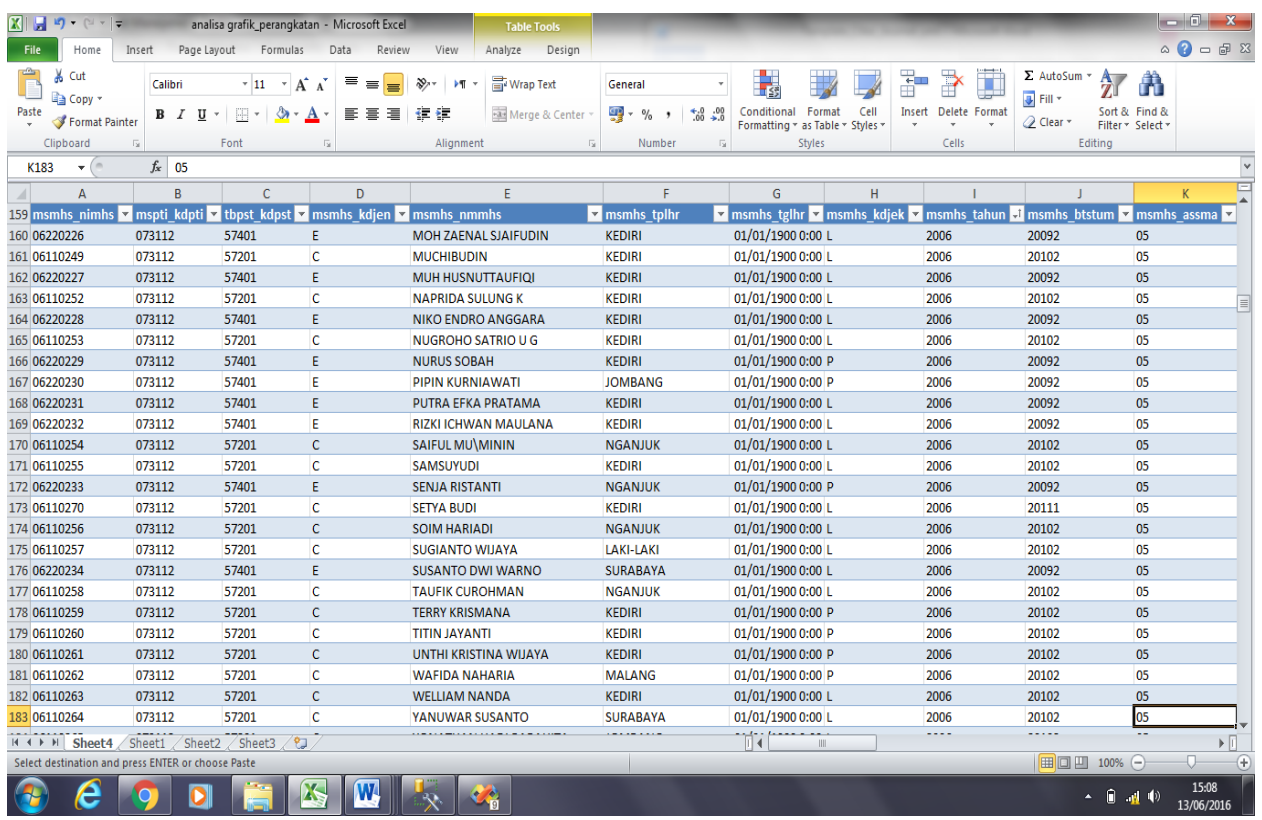

Gambar 11. Tampilan Data Mahasiswa 


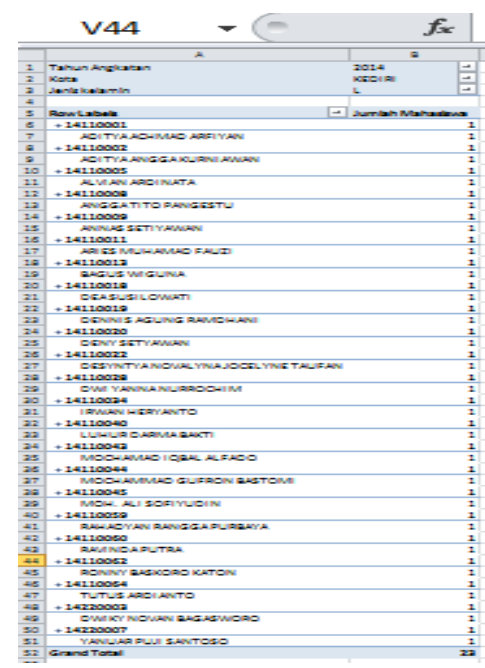

Gambar 12. Laporan Jumlah Mahasiswa Per Angkatan, Per Asal Kota Dan Per Jenis Kelamin.

b. Penyajian Grafik

Untuk melihat perkembangan jumlah mahasiswa per angkatan, per jenis kelamin dan perkota asal dapat dibuatlah grafik seperti dibawah ini

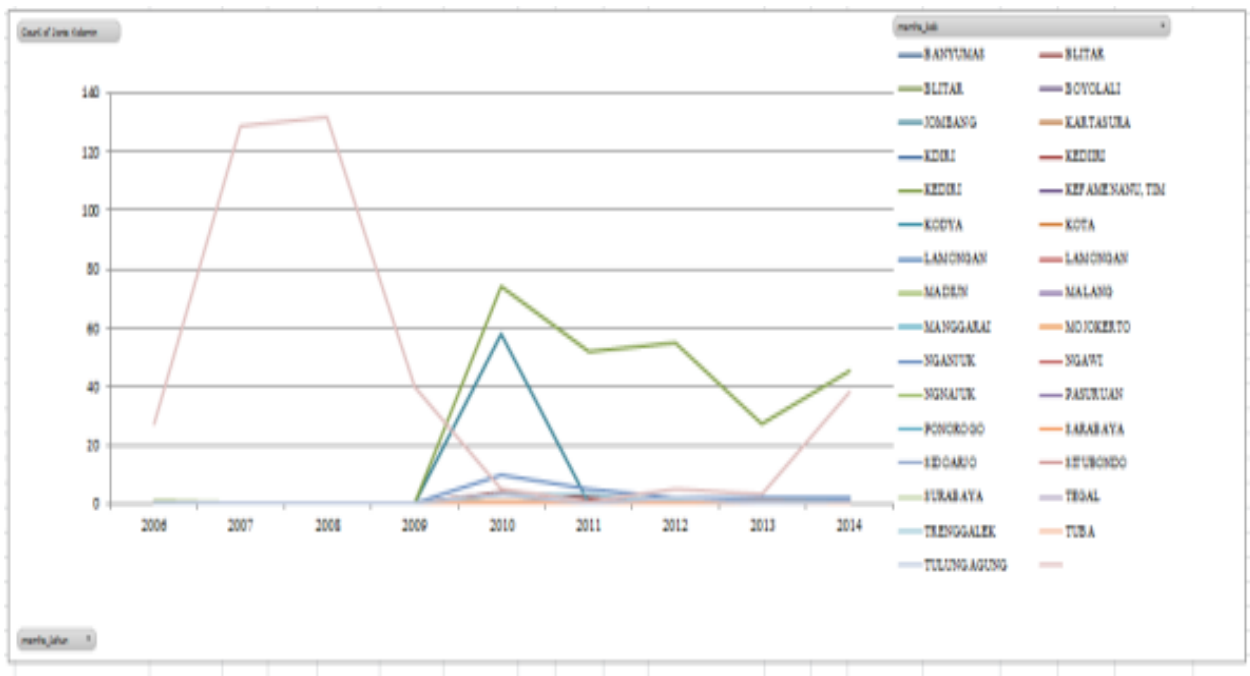

Grafik 13. Grafik jumlah mahasiswa Per Angkatan, Per Kota Asal dan Per Jenis Kelamin

Pembahasan :

Pada grafik diatas menunjukkan bahwa jumlah mahasiswa paling banyak berasal dari Kediri dari semua angkatan. Laporan ini akan dimanfaatkan oleh manajemen dalam mengambil keputusan strategis seperti untuk promosi dan kebutuhan untuk pelaporan EPSBED STMIK Kadiri. 


\section{KESIMPULAN}

Dihasilkan rancangan data warehouse pada sekolah tinggi melalui tahapan menentukan jenis informasi yang akan ditampilkan, mengidentifikasi sumber data serta mentransfer informasi dari sumber data transaksional ke dalam data warehouse melalui proses extract, transform dan loading kemudian dari data warehouse ditransformasikan ke multidimensional data untuk keperluan analisis dan menyajikan informasi kepada pengguna akhir dilingkungan manajemen tingkat atas.

Tahapan perancangan data warehouse menghasilkan rancangan arsitektur logic dan fisik yang dapat digunakan dalam pengembangan PDPT perguruan tinggi yang membantu untuk mendukung kebutuhan data EPSBED khususnya yang ada di STMIK Kadiri.

\section{SARAN}

Saran yang diberikan agar dapat memperoleh hasil yang lebih baik dan bermanfaat, yaitu

1. Pengembangan aplikasi yang telah ada, sehingga data-data dalam jumlah besar terorganisir, terkelompok dan lebih mudah diproses guna meningkatkan pelayanan mahasiswa STMIK Kadiri secara keseluruhan. Perancangan data warehouse yang ada diharapkan dapat diimplementasikan dan diperluas.

2. Dengan tersedianya laporan dengan pivotable excel diharapkan membantu manejemen dalam mengambil keputusan strategis secara cepat dan mudah. Penelitian ini masih banyak kekurangan data yang disajikan masih sedikit untuk itu perlu dikembangkan lebih lanjut.

\section{UCAPAN TERIMA KASIH} kepada:

Pada kesempatan ini diucapkan terimakasih dan penghargaan yang setulus-tulusnya

1. Kedua Orang Tuaq yang senantiasa memanjatkan do'a untuk kesuksesan anaknya dan memberikan dorongan semangat hingga tersusunnya Tesis ini.

2. Suami dan Anakq tercinta, dua orang yang selalu menjadi kekuatan $\mathrm{n}$ spiritq ,terima kasih banyak atas dukungan dan motivasi kalian sehingga tesis ini dapat terselesaikan dengan baik.

3. Prof. Dr. M. Suyanto, M.M selaku Ketua STMIK Amikom Jogyakarta yang selalu memberikan dorongan motivasi kepada mahasiswa.

4. Dr. Kusrini.,M.Kom selaku Direktur Program Pascasarjana STMIK Amikom Jogyakarta yang selalu memberikan dorongan motivasi kepada mahasiswa.

5. Dr. Wing Wahyu Winarno, MAFIS, Ak selaku dosen pembimbing I yang banyak memberikan arahan dan masukan.

6. Armadyah Amborowati, S.Kom., M.Eng selaku dosen pembimbing II yang banyak memberikan arahan dan masukan.

7. Semua Dosen Pengajar di Program Pascasarjana STMIK AMIKOM Yogyakarta terima kasih banyak atas ilmu-ilmu yang telah diberikan semoga bisa bermanfaat dunia dan akhirat.

8. Ibu Tri Estri Rahayuningtyas,S.E.,M.M selaku ketua STMIK Kadiri yang telah memberikan ijin untuk melakukan penelitian di STMIK Kadiri dan memberikan informasi serta data - data yang dibutuhkan oleh penulis.

9. Bapak Moch.Imadudin,S.E selaku pimpinan LKP.Terra Computer System Kediri dan teman2 yang ada di TCSK terima kasih atas dukungannya dan doanya selama ini. 
10. Rekan-rekan sesama mahasiswa MTI seperjuangan yang senantiasa berdiskusi untuk mencari berbagai solusi, juga disampaikan terimakasih.

11. Ucapan terimakasih juga disampaikan kepada pihak-pihak lain yang tidak dapat disebutkan satu persatu, yang telah banyak membantu dalam menyelesaikan tesis ini.

Disadari bahwa tesis ini masih banyak kekurangan, maka diharapkan tegur sapa, kritik, dan saran-saran, dari berbagai pihak sangat diharapkan. Akhir kata, semoga tesis ini dapat memberikan manfaat bagi kita semua, khususnya bagi dunia pendidikan.

\section{DAFTAR PUSTAKA}

[1 ]. Inmon, W. H. 2005. Building the data warehouse. John wiley \& sons.

[2 ]. Wikramanayake, G. N., \& Goonetillake, J. S. 2009. Managing Very Large Databases and Data Warehousing. Sri Lankan Journal of Librarianship and Information Management, 2(1). (pp.22-29)

[3 ]. Goldstein, P. J., \& Katz, R. N. 2005. Academic analytics: The uses of management information and technology in higher education. ECAR, (pp. 1-12), December 2005

[4 ]. Warnars, S. (2010). Tata Kelola Database Perguruan Tinggi Yang Optimal Dengan Data Warehouse. TELKOMNIKA,vol. 8, no. 1, (pp. 25-34)

[5 ]. Azimah, A., \& Sucahyo, Y. G. 2007. Implementasi Data Warehouse untuk Menunjang kegiatan Akademik ${ }^{e e}$. In Seminar Nasional Sistem dan Informatika 2007 (pp. 270-275).

[6 ]. Amo, B. C., \& Amo, W. C. 2000. Microsoft SQL Server 7 OLAP Developer's Guide. Hungry Minds, Incorporated.

[7 ]. Hasibuan, Z. A. 2007. Metodologi Penelitian Pada Bidang Ilmu Komputer dan Teknologi Informasi. Konsep: Metode Teknik dan Aplikasi, Depok.

[8 ]. Henderi, H., \& Winarko, E. 2015. Rancangan Sistem Data Warehouse Evaluasi Kinerja. SEMNASTEKNOMEDIA, 3(1), (pp.4.6-13). 6-8 Februari 2015

[9 ]. Rahayu, G. P., \& Gunawan, R. 2013. Penerapan Slowly Changing Dimensions untuk Mendukung Pembentukan Dimensi Dinamis Pada Data Warehouse. In Seminar Nasional Aplikasi Teknologi Informasi (SNATI), Yogyakarta, (pp. F-33-38).

[10 ]. Ponniah, P. 2001. Data Warehousing fundamentals, John Willey \& Sons.Inc, New York, USA. 